\section{CONSERVATION \\ Poverty drives forest raiders}

Researchers have proposed ways to improve efforts to stop people illegally harvesting wood and food from a conservation park in Uganda.

Bwindi Impenetrable National Park, which covers 330 square kilometres, hosts half of the world's endangered mountain gorillas. Mariel Harrison at Imperial College London and her colleagues surveyed 365 households around Bwindi and found that people in $26 \%$ of them had hunted for bushmeat and 20\% had collected firewood in the park. These illegal activities were most prevalent among the poorest households living in remote areas and closest to the park. Focus groups reported poverty and resentment at the inequitable distribution of benefits from the park as reasons for their activities.

The researchers suggest that projects combining conservation and development should benefit the poorest people in remote areas near park boundaries to reduce illegal activities that jeopardize the park's resources.

Conserv. Biol. http://doi.org/6nt (2015)

\section{NEURODEVELOPMENT}

\section{Mouse brain cells made primate-like}

By turning on a single gene in specific neural cells in the embryonic mouse brain, researchers have made more neurons grow in the neocortex - a region that evolved to be much larger in primates than in other mammals.

Wieland Huttner at the Max Planck Institute of Molecular Cell Biology and Genetics in Dresden, Germany, and his

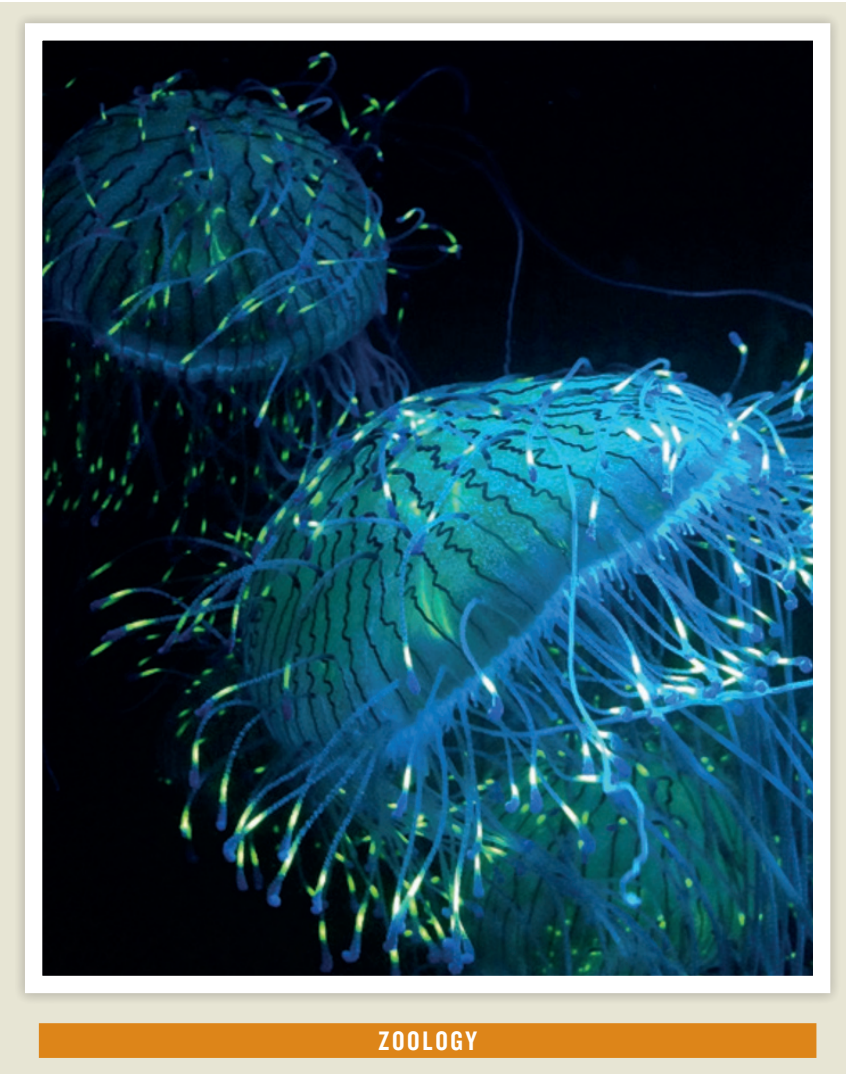

\title{
Light show lures prey
}

Jellyfish and other marine animals could be using their fluorescent proteins to attract prey.

Proteins such as green fluorescent protein (GFP) are invaluable tools for biologists in the lab, but their role in nature has not been clear. Steven Haddock at Monterey Bay Aquarium Research Institute in Moss Landing, California, and Casey Dunn at Brown University in Providence, Rhode Island, placed the flower hat jellyfish (Olindias formosus, pictured in blue light) in a tank along with its rockfish prey and separated the two with a transparent wall. When they exposed $O$. formosus to blue light (the light of its underwater habitat), the tips of its tentacles fluoresced green and the rockfish attacked the barrier more often than under yellow or white light or when the jellyfish was replaced with a non-fluorescent decoy.

Herbivorous prey may be seeing the fluorescence as an indicator of chlorophyll, which also fluoresces.

Biol. Open http://doi.org/6qd (2015)

team developed a mouse model in which they could switch on the Pax6 gene in specific neural progenitor cells - where it is expressed in humans but not in mice. They turned on the gene in cells that give rise to neurons of the neocortex, which controls advanced cognitive abilities. The team found that with sustained Pax6 expression, the progenitor cells proliferated more, resulting in more neurons in parts of the neocortex.

Pax6 could have had an important role in the evolution of the larger primate neocortex, the authors suggest PLoS Biol. 13, e1002217 (2015)

\section{ASTRONOMY \\ Stars align to show new planet}

Two teams using different telescopes have confirmed that a planet with a mass similar to that of Uranus is orbiting a distant star.

Most known exoplanets orbit close to their stars, but in 2005 researchers using an effect called microlensing spotted a planet with a larger orbit. This effect happens when two stars align: the gravity of the star in front magnifies light from the one behind. Planets in the foreground system can alter this light, which allows them to be detected.

David Bennett at the University of Notre Dame in Indiana and his colleagues used NASA's Hubble Space Telescope to study the light from the microlensing event OGLE-2005-BLG-169 more precisely. Their observations indicated the presence of a planet roughly 14 times heavier than Earth and more than 3 times farther from its star.

Another team that included Bennett, led by Virginie Batista of the Paris Institute of Astrophysics, used the W. M. Keck Observatory in Hawaii and found similar properties for the planet. Astrophys. J. 808, 169; Astrophys. J. 808, 170 (2015)

\section{VACCINOLOGY}

\section{How the Ebola vaccine protects}

The Ebola vaccine that proved effective in a trial of more than 4,000 people in Guinea seems 